\title{
The Role of Spirituality Healing with Perceptions of the Medical Encounter among Latinos
}

\author{
Carlos A. Reyes-Ortiz, MD, $P h D^{7}$, Michael Rodriguez, MD, MPH ${ }^{2}$, and Kyriakos S. Markides, $P h D^{3}$ \\ 'Department of Social \& Behavioral Sciences (CARO), School of Public Health, University of North Texas Health Science Center, Fort Worth, TX, USA; \\ ${ }^{2}$ Department of Family Medicine (MR), David Geffen School of Medicine, UCLA, Los Angeles, CA, USA; ${ }^{3}$ Department of Preventive Medicine \\ \& Community Health (KSM), University of Texas Medical Branch, Galveston, TX, USA.
}

BACKGROUND: Little is known about the relationship between spirituality healing and perceptions about the medical encounter among Latinos.

OBJECTIVES: To examine the association between spirituality healing and attitudes of self-reported perceptions about the medical encounter.

DESIGN: A cross-sectional telephone survey.

PARTICIPANTS: 3,728 Latinos aged $\geq 18$ years residing in the United States from Wave 1 of the Pew Hispanic Center/Robert Wood Johnson Foundation Latino Health Survey.

MEASUREMENTS: Dependent variables were ever prayed for healing (yes/no), ever asked others to pray for healing (yes/no), considered important spiritual healing (very vs. somewhat or not important), and ever consulted a 'curandero' (folk healer in Latin America) (yes/no). The primary independent variables were feelings about the last time seeing a Doctor (confused by information given, or frustrated by lack of information) and perception of quality of medical care (excellent, good, fair or poor) within the past 12 months.

RESULTS: Six percent of individuals reported that they had ever consulted a curandero, $60 \%$ prayed for healing, $49 \%$ asked others to pray for healing, and $69 \%$ considered spiritual healing as very important. In multivariable analyses, feeling confused was associated with increased odds of consulting a curandero $(\mathrm{OR}=1.58$; 95\% CI, 1.02 2.45), praying for healing $(\mathrm{OR}=1.30 ; 95 \% \mathrm{CI}, 1.03-1.64)$, asking others to pray for healing $(\mathrm{OR}=1.29$; 95\% CI, 1.031.62), and considering spiritual healing as very important $(\mathrm{OR}=1.30 ; 95 \% \mathrm{CI}, 1.01-1.66)$. Feeling frustrated by a lack of information was associated with asking others to pray for healing $(\mathrm{OR}=1.29$; 95\% CI, 1.04-1.60). A better perception of quality of medical care was associated with lower odds of consulting a curandero $(\mathrm{OR}=0.83$; 95\% CI, 0.70-0.98).

CONCLUSION: Feelings about the medical encounter were associated with spirituality healing, praying for healing, and asking others to pray for healing. Feeling confused and perception of poor quality of medical care were associated with consulting a curandero.
KEY WORDS: Latinos; medical encounter; spirituality healing; praying for healing; curanderos.

J Gen Intern Med 24(Suppl 3):542-7

DOI: $10.1007 /$ s11606-009-1067-9

(C) Society of General Internal Medicine 2009

\section{INTRODUCTION}

Spirituality along with religious beliefs and practices is common among patients seeking medical care. Spirituality is more individualistic and self-determined, whereas religion typically involves connections to a community with shared beliefs and rituals. However, there is an overlap between religiosity and spirituality where nearly 90\% of medical patients consider themselves both religious and spiritual. ${ }^{1}$

Spirituality and religiosity, when used for the purpose of healing or to maintain health, are important components of mind-body alternative therapies, commonly used by minority populations, and particularly by Latinos. ${ }^{2-7}$ Spirituality and religiosity are common with Latino cultural values and daily lives, serve as foundations of strength and coping with life's struggles, as well as playing an important role as alternative therapy for health and well-being. 8,9

The majority of individuals appear to use alternative therapies or consult alternative practitioners in conjunction with, rather than instead of, more conventional medical treatment. ${ }^{10}$ Potential reasons for using alternative therapies include barriers to obtaining care, dissatisfaction with conventional treatment, having desire for control over health, philosophical congruence (i.e., holistic view of life), cultural beliefs, and factors related to the physician-patient relationship. ${ }^{10-14}$ Also, patients' use of spirituality healing is associated with barriers to obtaining care and dissatisfaction with the quality of care given by their medical provider. ${ }^{12}$

Key components of the physician-patient relationship such as information sharing and perceived quality of care may determine patients' satisfaction with medical care, ${ }^{15,16}$ and, at the same time, may determine use of alternative therapies or practitioners. ${ }^{12,14}$ Furthermore, patients may feel frustrated during the medical encounter when they have a sense of being inadequately informed or excluded from information about health issues or disease knowledge. Patients may also feel confused during the medical encounter when they have difficulty understanding the language and terminology of health professionals. ${ }^{17}$ Both feeling frustrated or confused may create a sense of miscommunication during the medical 
encounter and weaken patients' confidence in the prescribed treatment regimen and their ability to engage with it. ${ }^{15,17}$

There is little information in the literature on the relationship between spirituality healing or curandero use and feelings on regarding the physician-patient communication or the perception of quality of care among Latinos. The purpose of this analysis was to examine the association between spirituality healing or curandero use and feelings (confusion, frustration) about the information provided during the medical encounter or perception of quality of medical care among Latinos.

\section{METHODS}

\section{Data Source}

Data are from Wave 1 of the Pew Hispanic Center/Robert Wood Johnson Foundation Latino Health Survey. This survey was conducted from July 16 to September 23, 2007, with a nationally representative sample of 4,013 randomly selected US Latino adults aged $\geq 18$ years living in the United States. The overall response rate for this study was $46.3 \%$. A total of 1,320 respondents were surveyed in English and 2,639 in Spanish (and 54 were interviewed in both languages). ${ }^{18}$ After excluding 166 participants who refused to answer critical questions, a total of 3,847 respondents remained for analysis. All the interviews were conducted using the Computer Assisted Telephone Interviewing (CATI) system. ${ }^{18}$ Data were weighted using a two-stage weighting design to ensure an accurate representation of the national Latino population. The first stage takes the disproportionality of the stratified design (under-sampled or over-sampled cases) and rebalances cases back to nationally representative counts of Hispanics. The second stage comprised of post-stratification weighting to nationally representative counts of Latinos by region, age, education, heritage, born in US/years in US, and gender. An industry standard ranking program was utilized to produce final post-stratification weights. ${ }^{18}$

\section{Measures}

Outcomes. For the purposes of this analysis, we included three mind-body alternative behaviors and attitudes (praying for healing, asking others to pray for healing and identifying the importance of spiritual healing), and one alternative therapy delivered by a practitioner (consulting a curandero [folk healer]) that are commonly used by Latinos according to the literature. ${ }^{2-7}$ Consulting a curandero was assessed by asking: "Do you ever seek help from a curandero, a shaman or someone else with special powers to heal the sick?" (yes/no). Praying for healing was assessed by asking: "Have you ever prayed specifically to be healed of an illness or injury?" (yes/ no). Asking others to pray for healing was assessed by asking: "Have you ever asked others to pray for you to be healed of an illness or injury?" (yes/no). The importance of spiritual healing was assessed by the questions: "How important is spiritual healing in maintaining your health and well being? Would you say very important, somewhat important, slightly important or not at all important?" The original unweighted percentages based on the analytical sample used for those responses were $69.2 \%$ (very), $19.4 \%$ (somewhat), $5.3 \%$ (slightly) and $6.1 \%$ (not at all). Since the proportional odds assumption was violated when using as ordinal outcome, we dichotomized this variable as very important vs. somewhat/ slightly/not at all important.

Independent Variables. Based on previous qualitative and quantitative research conducted predominately on non-Hispanic populations, ${ }^{12-17}$ we selected as primary independent variables those variables we hypothesized as potential correlates of the outcomes. These were perception of quality of medical care and feelings toward the last medical encounter. Perception of quality of medical care was assessed by the question: "Overall, how would you rate the quality of medical care that you have received in the past 12 months? Was the medical care excellent (code=4), good ( code=3), fair $(\operatorname{code}=2)$, or poor $(\operatorname{code}=1)$ ?". Feelings toward the last medical encounter were assessed by the following two questions: "Thinking about the last time you saw a doctor or other medical professional for any reason, did you feel any of the following things?...At any point, did you feel... 1) Confused by the information you were given? (yes/no); and 2) frustrated by a lack of information or an inability to find what you wanted to know?" (yes/no).

Based on the literature, we included as control variables other potential correlates for mind-body alternative therapies or curandero utilization among Latinos, such as sociodemographic factors, nativity status, self-rated health, diabetes, and depression. ${ }^{2-7,19-27}$

Sociodemographic variables were age (years, 18-49 and 50+), sex , marital status (married, unmarried), education (in years, 0-11 and 12+), type of Hispanic/ Latino origin (Mexican, Puerto Rican, Cuban, Central/South American, and other Latino), health insurance coverage (any, private, Medicare or Medicaid vs. none), and having a usual source of health care (yes/ no). Nativity status was determined as US-born and foreign-born. Diabetes and depression were assessed asking the respondents if they had ever been told by a doctor or other health care provider that they had diabetes (or high blood sugar; any other time than during pregnancy for women) (yes / no), and depression (yes/ no). Self-rated health was assessed by the question: "In general, how would you describe your own health? Would you say it is excellent (code=5), very good $(\operatorname{code}=4)$, good $(\operatorname{code}=3)$, fair $(\operatorname{code}=2)$ or poor $(\operatorname{code}=1)$ ?" We used this variable as ordinal (from 1 to 5 ).

Statistical Analysis. All analyses were performed using the SAS System for Windows, version 9.1 (SAS Institute, Inc., Cary, NC), significance level was set at $P<0.05$, two-tailed. Complex design effects (strata and weights) were incorporated utilizing the SURVEY procedure in SAS. To describe characteristics of the study population, we used descriptive statistics (unweighted frequencies and percentages or means). We performed correlation analyses (Spearman's $r h o=r_{s}$ ) between key health variables, primary independent variables (quality of medical care, feelings toward the medical encounter (confused, frustrated), and the outcomes. Multivariable weighted logistic regression analyses were performed to find independent correlates of the outcomes (curandero utilization, praying for healing, asking others to pray for healing, and importance of spiritual healing). Odds ratios (OR) with 95\% confidence intervals (CI) were calculated. 


\section{RESULTS}

Subjects with missing values for the dependent variables or the main independent variables (feeling confused or frustrated, and quality of care) were excluded. Those excluded $(n=119)$ were more likely to be low educated individuals who do not have usual source of health care, and to report poor or fair health compared to those who remained in the study $(n=3,728)$. Sixtyseven percent of the sample were between ages 18 and $49,50 \%$ were male, $64 \%$ were married, $54 \%$ had 12 or more years of education, and $64 \%$ were of Mexican's origin (Table 1, unweighted data. Sixteen percent of our sample reported diabetes, $65 \%$ rated their own health as excellent/very good or good, and $18 \%$ reported depression. After the last time seeing a doctor or other medical professional, $23 \%$ felt confused and $27 \%$ felt frustrated. Seventy-three percent felt that they received excellent or good quality of medical care in the past 12 months. Only $6 \%$ had ever consulted a curandero, $60 \%$ had ever prayed specifically to be healed of an illness, $49 \%$ had ever asked others to pray for healing, and $69 \%$ had considered spiritual healing to be very important.

In the correlation analyses, diabetes was positively correlated with depression $\left(r_{s}=0.13, p<.0001\right)$ and negatively correlated with self-rated health $\left(r_{s}=-0.22, p<.0001\right)$. Depression was negatively correlated with better self-rated health $\left(\mathrm{r}_{\mathrm{s}}=-0.17, \mathrm{p}<.0001\right)$. Feeling confused and frustrated were highly intercorrelated $\left(r_{s}=0.49, p<.0001\right)$, and confusion and frustration were moderately negatively correlated with perceived quality of medical care $\left(r_{s}=-0.14\right.$ and -0.20 respectively, both $\mathrm{p}<.0001)$. Spiritual healing was moderately correlated with praying to be healed $\left(r_{s}=0.29, p<.0001\right)$ and asking

Table 1. Characteristics of the Study Population $(N=3,728)$

\begin{tabular}{lc}
\hline \hline Demographic/ Health status & $\mathrm{n}(\%)^{*}$ \\
\hline Age (years, range 18-97) & $43.2+/-15.5$ (mean +/- SD) \\
Age 18-49 & $2515(67.5)$ \\
Male & $1858(49.8)$ \\
Married & $2388(64.0)$ \\
12+ years of education & $2029(54.4)$ \\
Any health insurance & $2430(65.2)$ \\
Has a usual source of health care & $2748(73.7)$ \\
Foreign born & $2786(74.7)$ \\
Hispanic/ Latino family's origin & \\
Mexican & $2371(63.6)$ \\
Puerto Rican & $309(8.3)$ \\
Cuban & $137(3.7)$ \\
Central/ South American & $749(20.1)$ \\
Other Latino & $162(4.3)$ \\
Self-rated health: Excellent, & $2414(64.7)$ \\
very good or good & $593(15.9)$ \\
Diabetes & $656(17.6)$ \\
Depression & \\
Main independent variables & $2231(23.4)$ \\
Feeling confused (yes) & $994(26.7)$ \\
Feeling frustrated (yes) & $2580(69.2)$ \\
Quality of medical care: & \\
$\quad$ Excellent or good & \\
Dependent variables & \\
Consulted a curandero & \\
Prayed to be healed & \\
Asked others to pray for healing & \\
Considered spiritual healing & \\
$\quad$ as very important & \\
\hline
\end{tabular}

* All data presented are unweighted others to pray for healing $\left(\mathrm{r}_{\mathrm{s}}=0.32, \mathrm{p}<.0001\right)$, while praying to be healed and asking others to pray for healing were highly intercorrelated $\left(r_{s}=0.45, p<.0001\right)$. Consulting a curandero was minimally associated with spiritual healing, praying to be healed and asking others to pray for healing $\left(r_{s}=0.05,0.05\right.$ and 0.06 , respectively; all $\mathrm{p}<.01$ ).

Table 2 shows the multivariable analyses for the primary correlates. Feeling confused after a medical encounter was significantly associated with consulting a curandero, praying to be healed, asking others to pray for healing, and considering spiritual healing as very important. Feeling frustrated after a medical encounter was only significantly associated with asking others to pray for healing. A better perception of quality of medical care was only significantly associated with lower odds of consulting a curandero.

Other significant independent correlates for consulting a curandero were being foreign-born (vs. US-born), being female, being of Cuban origin (vs. Mexican), and self-reporting fair/ poor health (vs. good/ very good/ excellent). Significant correlates for praying to be healed were: being between aged $18-49$ years vs. aged $\geq 50$ years, being female, having a usual place to go when sick, being depressed, and having diabetes. Significant correlates of asking others to pray for healing were: being foreign-born, being aged 18-49 years, being female, being depressed, and having diabetes. Finally, significant correlates for considering spiritual healing as very important were: being foreign-born, being aged 18-49 years, being female, being married, being of Central or South American origin, and being depressed.

\section{DISCUSSION}

We examined the relationship between spiritual healing or curandero use and feelings toward the information provided during the medical encounter (confusion, frustration) or perception of quality of medical care among adult Latinos. In multivariable analyses, we found that feeling confused by the information given during the last visit with a medical professional, was associated with consulting a curandero, praying for healing, asking others to pray for healing and considering spiritual healing very important. In additional analyses, we adjusted for the match between patient's language and medical provider's language at interview, and the association between feeling confused and the outcomes remained. Feeling frustrated was associated with asking others to pray for healing. Finally, a better perception of quality of medical care was associated with lower odds of consulting a curandero.

There is limited information in the literature about curandero use or mind-body therapies and their association with communication in the medical encounter or perception about quality of medical care. With partial agreement to our findings, in two separate studies, curandero utilization or increased use of spiritual therapy was associated to dissatisfaction with medical care received at the last visit to a medical practitioner. ${ }^{12,28}$ However, other studies showed no association between CAM use and satisfaction or communication during the medical encounter. In one study, CAM use was not associated with satisfaction with medical care received. ${ }^{29}$ In another study, Hispanic patients' CAM use was not associated with physician's communication about depression. ${ }^{30}$ 
Table 2. Multivariable Weighted Logistic Regression Models*

\begin{tabular}{|c|c|c|c|c|}
\hline & $\begin{array}{l}\text { Consulted } \\
\text { a curandero }\end{array}$ & $\begin{array}{l}\text { Prayed to } \\
\text { be healed }\end{array}$ & $\begin{array}{l}\text { Asked others to } \\
\text { pray to be healed }\end{array}$ & $\begin{array}{l}\text { Felt spiritual healing } \\
\text { was important }\end{array}$ \\
\hline & ORs $(95 \% \mathrm{Cl})$ & ORs $(95 \% \mathrm{Cl})$ & ORs $(95 \% \mathrm{Cl})$ & ORs $(95 \% \mathrm{Cl})$ \\
\hline Feeling confused, yes (ref. no) & $1.58(1.02-2.45)$ & $1.30(1.03-1.64)$ & $1.29(1.03-1.62)$ & $1.30(1.01-1.66)$ \\
\hline Feeling frustrated, yes (ref. no) & $1.23(0.78-1.95)$ & $1.10(0.88-1.38)$ & $1.29(1.04-1.60)$ & $0.96(0.76-1.22)$ \\
\hline Quality of care (score 1 to 4 ) & $0.83(0.70-0.98)$ & $0.99(0.90-1.09)$ & $1.02(0.92-1.12)$ & $1.00(0.90-1.12)$ \\
\hline \multicolumn{5}{|l|}{ Demographic } \\
\hline Age 18-49 (ref. 50+) & $1.34(0.89-2.02)$ & $0.80(0.65-0.97)$ & $0.75(0.62-0.90)$ & $0.60(0.48-0.74)$ \\
\hline Female (ref. male) & $0.63(0.44-0.89)$ & $1.22(1.02-1.46)$ & $1.21(1.02-1.43)$ & $1.41(1.17-1.69)$ \\
\hline Married (ref. unmarried) & $0.96(0.68-1.38)$ & $1.14(0.95-1.37)$ & $1.06(0.88-1.27)$ & $1.36(1.12-1.66)$ \\
\hline Education 0-11 years (ref. 12+) & $0.99(0.68-1.44)$ & $0.90(0.75-1.08)$ & $1.01(0.84-1.22)$ & $1.16(0.94-1.42)$ \\
\hline Any health insurance (ref. none) & $0.76(0.51-1.13)$ & $1.00(0.83-1.21)$ & $1.04(0.86-1.25)$ & $0.94(0.77-1.14)$ \\
\hline Has a usual source of health care (ref. no) & $0.98(0.63-1.52)$ & $1.30(1.06-1.59)$ & $1.13(0.92-1.38)$ & $1.04(0.83-1.29)$ \\
\hline \multicolumn{5}{|l|}{ Sub ethnicity (ref. Mexican) } \\
\hline Puerto Rican & $0.96(0.49-1.86)$ & $1.04(0.72-1.50)$ & $1.13(0.81-1.57)$ & $1.09(0.76-1.58)$ \\
\hline Cuban & $2.99(1.52-5.86)$ & $0.80(0.51-1.27)$ & $0.96(0.61-1.52)$ & $0.97(0.60-1.55)$ \\
\hline Central/ South American & $1.25(0.78-2.02)$ & $1.07(0.86-1.34)$ & $1.26(1.02-1.56)$ & $1.33(1.04-1.70)$ \\
\hline Other Latino & $1.61(0.67-3.89)$ & $1.32(0.85-2.06)$ & $1.00(0.65-1.53)$ & $1.54(0.99-2.39)$ \\
\hline Foreign-born (ref. US-born) & $0.58(0.39-0.86)$ & $1.12(0.92-1.38)$ & $1.22(1.01-1.51)$ & $1.51(1.21-1.88)$ \\
\hline \multicolumn{5}{|l|}{ Health status } \\
\hline Self-rated health (score 1 to 5 ) & $0.82(0.68-0.99)$ & $0.96(0.87-1.07)$ & $0.87(0.79-0.96)$ & $0.93(0.84-1.04)$ \\
\hline Depression, yes (ref. no) & $1.35(0.89-2.06)$ & $1.55(1.20-2.01)$ & $1.52(1.19-1.94)$ & $1.42(1.07-1.89)$ \\
\hline Diabetes, yes (ref. no) & $1.16(0.70-1.92)$ & $1.40(1.09-1.79)$ & $1.49(1.18-1.88)$ & $1.19(0.91-1.56)$ \\
\hline
\end{tabular}

*Odds ratios (ORs) and 95\% confidence intervals (CI) are presented

Curandero utilization (5.8\%) in our study appears slightly higher than reported in other population based studies exploring "ever" and "one-year" use but lower than that reported in convenience sample studies. Among Latinos in California, $3.2 \%$ reported ever having used a curandero. ${ }^{2}$ Likewise, using the HHANES, Higginbotham and colleagues ${ }^{29}$ reported that only $4.2 \%$ of Mexican American participants used a curandero (plus 'sobadores' [Traditional healers using massages to treat health problems], herbalists, spiritualists, and others) during a one-year period prior to the interview (1982-1984). In contrast, our curandero utilization rates are lower than reported in other studies using convenience samples of Latinos. For example, the utilization rates for ever used a curandero were $29 \%$ among Hispanics in an outpatient clinic in Colorado, ${ }^{31}$ and $26 \%$ among Mexican American women attending college. ${ }^{32}$ In another study, curanderos were used by $13 \%$ of Mexican American adults in the Texas Rio Grande Valley in the prior 12 months. ${ }^{33}$

A higher percentage of Latinos in our study (60\%) reported ever using prayer to be healed than reported by a general sample of US adults who pray for their own health $(52 \%){ }^{3}$ Because we used a separate measure from praying for healing, i.e., importance of spirituality for healing, we could not compare our spirituality measure $(69 \%$ very important vs. $31 \%$ somewhat/ slightly or not important) with other studies where both prayer and spirituality were combined and did not allow for reporting on the importance of spirituality alone. For example, in a study with a majority of non-Latino White elderly respondents, Cheung and colleagues ${ }^{34}$ reported a utilization of both spiritual healing and prayer in only $30 \%$. Keegan $^{33}$ reported that 67\% Mexican Americans used prayer and 28\% used spiritual healing in the past year. Although we did not include other CAM practitioners or therapies, our findings suggest that praying for healing and considering spiritual healing to be very important are common practices used by Latinos.
Data on religiosity or spirituality show differences across Latino subgroups or by nativity status. The large majority of Latinos in the US identify themselves as Catholic, ${ }^{35}$ though foreign-born Latinos are more likely to report being Catholic than are US-born Latinos who are somewhat more likely to be Evangelical or born-again Christians. Mexican Americans, Dominicans, Colombians and other South Americans are somewhat more likely to report they are Catholics. ${ }^{36,37}$ On the other hand, Latino seculars - no specific religious affiliation, atheist or agnostic - are predominantly male and younger compared with Latinos who identify as religious. ${ }^{36}$ Foreignborn Latinos are more likely than their US-born counterparts to indicate that religion is important in their life. Cubans are less likely than Mexicans, Puerto Ricans or other Central Americans to indicate that religion is very important in their life. Similarly, outside the US, older persons in Havana have the highest frequency of no religious affiliation compared to older persons in other Latin American and Caribbean cities. ${ }^{38}$ In our study, Puerto Ricans, Cubans and Central \& South Americans who were foreign-born had significantly higher percentages for considering spirituality healing as very important compared to their counterparts who were US-born.

The effect of nativity status on mind-body therapies or alternative practitioner use in our study is not uniform. Indeed, foreign-born Latinos were less likely to consult a curandero but more likely to ask others to pray for healing and were more likely to consider spiritual healing important compared with US-born Latinos (the most acculturated). Our findings agree ${ }^{27}$ or disagree ${ }^{2,21,29}$ from previous research that used different measures for acculturation, diverse groups of Latinos, or adjusted for other variables. Lee and colleagues ${ }^{27}$ reported that Mexican Americans who spoke English not well/ not at all were $68 \%$ less likely to use a curandero than those who spoke only English (the most acculturated), controlling for proportion of life spent in the US. In contrast, Latinos (Mexican 
Americans and other Latinos) who spoke English very well were six times more likely to have ever consulted a curandero than those who spoke only English (the most acculturated), controlling for religiosity and spirituality. ${ }^{2}$ In another study, foreign-born respondents, specifically recent immigrants $(<5$ years in the United States), were less likely to use prayer for healing than US-born subjects. ${ }^{21}$ Finally, higher acculturation (measured by a 5-item scale) was significantly associated with higher percentage of overall CAM use (practitioner based -e.g., chiropractic-, and self-care based- e.g., meditation and prayer) but with lower percentage of traditional folk remedies use. ${ }^{29}$ On the other hand, one study found no association between nativity status or language acculturation and curandero use. ${ }^{31}$

Our findings related to age and gender differences are important additions to the literature. Studies of CAM use among Latinos should cautiously consider overall CAM use because the use of some CAM modalities across age groups or gender may operate in opposite directions in this population. For example, in our study younger subjects were less likely to pray for healing, ask others to pray for healing and consider spiritual healing as very important, while other report, where overall CAM did not include prayer, showed that younger subjects were more likely to use overall CAM and most other CAM modalities than older subjects. ${ }^{3}$ Similarly, in our study women were less likely to consult a curandero but more likely to pray for healing, ask others to pray for healing and consider spiritual healing as very important compared to men. Neither gender nor age were associated with curandero use in four other studies. ${ }^{2,27,34,39}$ In one study, older age predicted curandero use. ${ }^{31}$ In other studies, compared to men, women had higher use of mind-body therapies (i.e., prayer), ${ }^{3,4,29}$ and traditional folk remedies (i.e., herbs). ${ }^{25,29}$

This study has some limitations. Our cross-sectional analyses could not establish causal order between certain variables and the dependent variables. Also, the time reference used for the questions was different. The time for most dependent variables was "ever," and the time for feelings toward the last medical encounter was not specifically defined, while the time for quality of medical care was within the last year. In addition, our questions for CAM modalities did not capture other types (i.e., herbal teas, dietary supplements, etc) that may be common among Latinos. ${ }^{4}$

This study may help physicians understand the use of prayer and spirituality among Latinos. Increased use of prayer and spirituality may be related to poorer quality of physicianpatient communications measured by the frustration or confusion related to provision of health care information. This underscores the importance of culturally and linguistically effective communication with Latinos who like most patients, want to be informed about their health. ${ }^{15}$ Latino patients should have clear information that which takes into account their unique cultural circumstances. ${ }^{8,11,40}$ On the other hand, use of spiritual healing practices that do not replace medical treatment should be viewed as attempts to increase potential benefit for health. The Latino patient tends to use spirituality as a common coping behavior. Indeed, a greater spirituality (specifically increased religiosity) among Latinos has been linked to health benefits such as: having better self-reported health, having less fear of falling, having fewer deaths, coping with cancer, maintaining better cognition and moderating the deleterious effect of depression on cognitive perfor- mance. ${ }^{38,41-46}$ Health care systems and clinicians that have supportive infrastructure and organizational systems for cultural competence facilitate patient care that is more cultural competent and may decrease patient frustration and confusion and improve the delivery of patient centered care.

In conclusion, we found that feelings about the medical encounter (confused or frustrated) were associated with spiritual healing, praying for healing, and asking others to pray for healing. Feeling confused and perception of poor quality of medical care were associated with consulting a curandero. More research is needed to further explore other measures of quality of care and characteristics of the medical encounter such as physicians' attitudes or behaviors related to spirituality for healing or curandero utilization among Latinos.

Acknowledgements: This project was supported by the Network for Multicultural Research on Health and Healthcare, Department of Family Medicine, David Geffen School of Medicine, University of California Los Angeles (U.C.L.A) funded by the Robert Wood Johnson Foundation. The sponsors had no role in the design, methods, data collection, and analysis, interpretation of data, decision for submission or writing of the manuscript. The interpretation and reporting of these data are the sole responsibilities of the authors.

\section{Conflict of Interest: None disclosed.}

Corresponding Author: Carlos A. Reyes-Ortiz, MD, PhD; Department of Social Behavioral Sciences (CARO), School of Public Health, University of North Texas Health Science Center, 3500 Camp Bowie Boulevard (EAD-711B), Fort Worth, TX 76107-2699, USA (e-mail: creyes@hsc.unt.edu).

\section{REFERENCES}

1. Koenig HG. Religion, spirituality, and medicine: research findings and implications for clinical practice. South Med J. 2004;97:1194-200.

2. Hsiao A-F, Wong MD, Goldstein MS, et al. Variation in complementary and alternative medicine (CAM) use across racial/ethnic groups and the development of ethnic-specific measures of CAM use. J Altern Complement Med. 2006;12:281-90.

3. Barnes P, Powell-Griner E, McFann K, Nahin RL. Complementary and alternative medicine use among adults: United States, 2002. Advance data from vital statistics; No. 343. Hyattsville, Maryland: National Center for Health Statistics; 2004: 1-20

4. Mikhail N, Wall S, Ziment I. Use of alternative medicine among Hispanics. J Altern Complement Med. 2004;10:851-9.

5. Kronenberg F, Cushman LF, Wade CM, Kalmuss D, Chao MT. Race/ ethnicity and women's use of complementary and alternative medicine in the United States: results of a national survey. Am J Public Health. 2006;96:1236-42.

6. Ortiz BI, Shields KM, Clauson KA, Clay PG. Complementary and alternative medicine use among Hispanics in the United States. Ann Pharmacother. 2007;41:994-1004.

7. Graham RE, Ahn AC, Davis RD. Use of complementary and alternative medical therapies among racial and ethnic minority adults: Results from the 2002 National Health Interview Survey. J Natl Med Assoc. 2005;97:535-45.

8. Campesino M, Schwartz GE. Spirituality among Latinas/os: implications of culture in conceptualization and measurement. ANS Adv Nurs Sci. 2006;29:69-81.

9. Levin J, Markides K, Ray L. Religious attendance and psychological well-being in Mexican Americans: a panel analysis of three-generations of data. Gerontologist. 1996;36:454-63.

10. Astin JA. Why patients use alternative medicine: Results of a national survey. JAMA. 1998;279:1548-53. 
11. Lee GBW, Charn TC, Chew ZH, Ng TP. Complementary and alternative medicine use in patients with chronic diseases in primary care is associated with perceived quality of care and cultural beliefs. Family Practice. 2004;21:654-60.

12. Ritchie CS, Gohmann SF, McKinney WP. Does use of CAM for specific health problems increase with reduced access to care? J Med Systems. 2005;29:143-53.

13. Chao MT, Wade C, Kronenberg F, Kalmuss D, Cushman LF. Women's reasons for complementary and alternative medicine use: racial/ethnic differences. J Altern Complement Med. 2006;12:719-20.

14. Shmueli A, Shuval J. Satisfaction with family physicians and specialists and the use of complementary and alternative medicine in Israel. Evid Based Complement Alternat Med. 2006;3:273-8.

15. Schattner A, Rudin D, Jellin N. Good physicians from the perspective of their patients. BMC Health Serv Res. 2004;4(1):26. Sep 12.

16. Nápoles-Springer AM, Livaudais JC, Bloom J, Hwang S, Kaplan CP. Information exchange and decision making in the treatment of Latina and white women with ductal carcinoma in situ. J Psychosoc Oncol. 2007;25(4):19-36.

17. Anderson K, Devitt J, Cunningham J, Preece C, Cass A. "All they said was my kidneys were dead": Indigenous Australian patients understanding of their chronic kidney disease. Med J Aust. 2008; 189:499-503.

18. Hispanics and Health Care in the United States: Access, Information and Knowledge. A joint pew hispanic center and robert wood johnson foundation research report. Washington, DC: August, 2008.

19. Grzywacz JG, Lang W, Suerken C, Guandt SA, Bell RA, Arcury TA. Age, race, and ethnicity in the use of complementary and alternative medicine for health self-management. J Aging Health. 2005; 17:547-72.

20. Pagan JA, Pauly Mv. Access to conventional medical care and the use of complementary and alternative medicine. Health Affairs. 2005;24:255-62.

21. Su D, Li L, Pagan JA. Acculturation and the use of complementary and alternative medicine. Soc Sci Med. 2008;66:439-53.

22. Pagán JA, Tanguma J. Health care affordability and complementary and alternative medicine utilization by adults with diabetes. Diabetes Care. 2007;30:2030-1.

23. Bazargan M, Ani Co, Hindman DW, et al. Correlates of complementary and alternative medicine utilization in depressed, underserved African American and Hispanic patients in primary care settings. J Altern Complement Med. 2008;14:537-44.

24. Keith VM, Kronenfeld JJ, Rivers PA, Liang S-Y. Assessing the effects of race and ethnicity on use of complementary and alternative therapies in the USA. Ethn Health. 2005; 10:19-32.

25. Loera J, Reyes-Ortiz CA, Kuo YF. Predictors of complementary and alternative medicine use among older Mexican Americans. Complement Ther Clin Pract. 2007;13:224-31.

26. Mackenzie ER, Taylor L, Bloom BS, Hufford DJ, Johnson JC. Ethnic minority use of complementary and alternative medicine (CAM): a national probability survey of CAM utilizers. Altern Ther Health Med 2003;9(4):50-6.

27. Lee JH, Goldstein MS, Richard Brown E, Ballard-Barbash R. How does acculturation affect the use of complementary and alternative medicine providers among Mexican- and Asian- Americans? J Immigr Minor Health. 2008 Aug 3. [Epub ahead of print]
28. Higginbotham JC, Trevino FM, Ray LA. Utilization of curanderos by Mexican Americans. Prevalence and predictors. Findings from HHANES 1982-84. Am J Public Health. 1990;80(suppl):32-5.

29. Palinkas LA, Kabongo ML. San Diego unified practice research in family medicine network. The use of complementary and alternative medicine by primary care patients. A SURF*NET study. J Fam Pract. 2000;49:1121-30.

30. Sleath BL, Williams JW Jr. Hispanic ethnicity, language, and depression: physician-patient communication and patient use of alternative treatments. Int J Psychiatry Med. 2004;34:235-46.

31. Padilla R, Gomez V, Biggerstaff SL, Mehler PS. Use of curanderismo in a public health care system. Arch Intern Med. 2001;161:1336-40.

32. Lopez RA. Use of alternative folk medicine by Mexican American women. J Immigr Health. 2005; 7:23-31.

33. Keegan L. A comparison of the use of alternative therapies among Mexican Americans and Anglo-Americans in the Texas Rio Grande Valley. J Holist Nurs. 2000;18:280-95.

34. Cheung CK, Wyman JF, Halcon LL. Use of complementary and alternative therapies in community-dwelling older adults. J Altern Complement Med. 2007;13:997-1006.

35. Espinosa G, Elizondo V, Miranda J. Hispanic Churches in American Public Life: Summary of findings, 2003. Accessed May 15, 2009 at: http://www. nd.edu/\%7Elatino/research/pubs/HispChurchesEnglishWEB.pdf

36. Pew Research Center. Changing faiths: Latinos and the transformation of American religion. Washington, DC: Pew Research Center; 2007.

37. Pew Hispanic Center/ Kaiser Family Foundation 2002 National Survey on Latinos. 2002. Accessed on May 12, 2009 at: http://www.kff.org/ kaiserpolls/upload/2002-National-Survey-of-Latinos-Summary-of-Find ings.pdf

38. Reyes-Ortiz CA, Pelaez M, Koenig HG, Mulligan T. Religiosity and selfrated health among Latin American and Caribbean elders. Int $\mathrm{J}$ Psychiatry Med. 2007;37:425-43.

39. Kuo GM, Hawley ST, Weiss LT, Balkrishnan R, Volk RJ. Factors associated with herbal use among urban multiethnic primary care patients: a crosssectional survey. BMC Complement Altern Med. 2004 Dec 2; 4:18.

40. Engebretson J. Culture and complementary therapies. Complement Ther Nursing Midwifery. 2002;8:177-84.

41. Reyes-Ortiz CA, Ayele H, Mulligan T, Espino DV, Berges IM, Markides KS. Higher church attendance predicts lower fear of falling in older Mexican Americans. Aging Ment Health. 2006;10:13-8.

42. Hill TD, Angel JL, Ellison CG, Angel RJ. Religious attendance and mortality: an 8-year follow-up of older Mexican Americans. J Gerontol B Psychol Sci Soc Sci. 2005;60:S102-9.

43. Levine EG, Yoo G, Aviv C, Ewing C, Au A. Ethnicity and spirituality in breast cancer survivors. J Cancer Surviv. 2007;1:212-25.

44. Nápoles-Springer AM, Ortíz C, O'Brien H, Díaz-Méndez M, PérezStable EJ. Use of cancer support groups among Latina breast cancer survivors. J Cancer Surviv. 2007;1:193-204.

45. Hill TD, Burdette AM, Angel JL, Angel RL. Religious attendance and cognitive functioning among older Mexican Americans. J Gerontol Psychol Sci Soc Sci. 2006;61B:3-9.

46. Reyes-Ortiz CA, Berges IM, Raji MA, Koenig HG, Kuo YF, Markides KS. Church attendance mediates the association between depressive symptoms and cognitive functioning among older Mexican Americans. J Gerontol A Biol Sci Med Sci. 2008;63A:480-6. 